\title{
DISCURSO DE POSSE DO PROFESSOR ANTONIO MAGALHÃES GOMES FILHO, COMO TITULAR DE DIREITO PROCESSUAL DA FACULDADE DE DIREITO DA UNIVERSIDADE DE SÃO PAULO
}

\author{
Antonio Magalhães Gomes Filho \\ Professor Titular de Direito Processual da Faculdade de \\ Direito da Universidade de São Paulo
}

Ao me dirigir à douta Congregação da Faculdade de Direito, na qualidade de seu novo titular de Direito Processual Penal, não consigo abandonar o vezo de processualista e resistir à tentação de interpretar o ritual observado nesta sessão solene à luz dos conceitos da teoria do processo.

À semelhança do que ocorre em relação às formalidades prescritas para os diversos atos do procedimento judicial, que não constituem encenações inúteis, mas antes representam um meio para que se alcancem determinadas finalidades e se afirmem valores mais elevados na tarefa de realização da Justiça, os ritos observados em "cerimônias" ou "solenidades" como esta também objetivam reforçar ideais, suscitar sentimentos e, de forma geral, destacar aspectos importantes de um acontecimento singular na vida da instituição universitária.

Assim, em primeiro lugar, a escolha de um local suntuoso e austero como este Salão Nobre, a presença da Congregação em assentos determinados no doutoral, o uso das becas, a introdução no recinto dos novos professores pelos membros mais antigos da Congregação, e, enfim, as palavras de recepção (que no meu caso foram especialmente generosas), traduzem, a meu ver, uma clara advertência: a de que o ingresso como professor titular nesta Casa não constitui um fato original, um início, mas antes um acontecimento que se insere na vida de uma instituição centenária como continuidade de atribuições docentes que aqui foram exercidas superiormente por antecessores ilustres que dignificaram a cátedra, transmitindo a numerosas gerações de bacharéis os ensinamentos básicos da Ciência do Direito.

No caso da cadeira de Direito Processual Penal, que passo a ocupar como professor titular, é um verdadeiro privilégio - mas ao mesmo tempo uma grave responsabilidade - dar prosseguimento a uma tarefa desempenhada de forma tão proficua por mestres cujas lições marcaram significativamente a cultura jurídica deste País.

É preciso destacar, a propósito, que o ensino dessa disciplina entre nós, antes relegado às condição de simples capitulo do Direito Penal ou de setor menos nobre da Prática Forense, conquistou definitiva autonomia com a passagem do grande João Mendes Júnior pela cátedra. $\mathrm{E}$ foi a partir de então que se superou a antiga divisão do Direito Penal em direito substantivo e direito adjetivo, fincando-se as bases para uma concepção do Processo Penal como conjunto de preceitos garantidores das liberdades individuais, pois, como ressaltava o mestre em texto clássico de nossa 
literatura juridica, "as leis do processo são o complemento necessário das leis constitucionais e as formalidades do processo são as atualidades das garantias constitucionais"

Também não me é possível assumir a cadeira de Processo Penal desta Casa sem ter presente na memória a inesquecivel figura de Joaquim Canuto Mendes de Almeida, meu professor no curso de graduação e orientador no mestrado. Sua personalidade exuberante e sua luminosa inteligência deixaram marcas indeléveis em setores dos mais diversos da nossa vida cultural. Autor e diretor de cinema, cuja obra pioneira nesse campo foi inclusive tema de recente dissertação defendida no Departamento de História da Faculdade de Filosofia, Letras e Ciências Humanas desta Universidade, foi também músico e político na mais nobre acepção do termo, destacando-se sobretudo pela defesa dos direitos sociais.

Não foi menor, nem menos original, a sua contribuição para o aprimoramento dos estudos de Direito Processual Penal. Preocupando-se, já na década de 1930, com o que hoje em dia constitui o centro de atenção de toda a ciência do processo, mestre Canuto fixou entre nós a importância do conceito essencial de contraditório; além disso, concebendo o processo judiciário como direito fundamental, não do autor, mas do réu, na medida em que tutela precipuamente a liberdade jurídica deste em face de uma possível coação estatal, antecipou algumas teses que embasam a atualíssima teoria do garantismo penal e processual penal.

Mais séria ainda é a responsabilidade de suceder imediatamente no cargo de professor titular ao prezadíssimo professor Rogério Lauria Tucci, com quem muito aprendi, primeiramente como aluno de pós-graduação e, depois, nas atividades docentes e de diversas comissões de elaboração legislativa. Pesquisador incansável, jurista na mais completa acepção do termo, com vasta produção científica em diversas áreas do Direito, dedicou-se com invejável proficiência ao estudo dos temas mais relevantes da Ciência Processual, destacando-se em especial a mais completa e ampla obra de sistematização dos direitos e garantias individuais no Processo Penal brasileiro.

É necessário também ressaltar o meu privilégio, minha enorme felicidade, em poder compartilhar, a partir de agora, a docência de Processo Penal nesta Casa com Ada Pellegrini Grinover, minha orientadora no Doutorado e responsável, juntamente com o amigo Cândido Rangel Dinamarco, pelo meu ingresso na carreira docente.

Líder da "Nova Escola Processual de São Paulo", cujo reconhecimento e importância podemos constatar, com justificado orgulho, em numerosos congressos internacionais, Ada tem a sua obra marcada pela constante preocupação com a mudança do processo, de intrumento puramente técnico, em instrumento ético e político de atuação da Justiça e de garantia da liberdade e pela busca da efetividade da tutela jurisdicional e das garantias processuais, numa perspectiva abrangente, que leve em conta a emergência dos direitos sociais. Dentre as suas incontáveis virtudes, a mais evidente é, sem dúvida, a generosidade, que não se manifesta exclusivamente na benevolente apreciação das qualidade de seus discípulos e amigos como todos aqui puderam há pouco constatar -, mas se revela sobretudo na permanente disposição de 
colocar a sua fina percepção dos problemas atuais do Direito, o rigor de sua formação científica, o brilho de sua inteligência e o ardor da sua combatividade a serviço da causa comum de aprimoramento das nossas instituições e do ensino jurídico.

A segunda e importante constatação que extraio do ritual desta solenidade, e que decorre da honrosa concessão da palavra neste momento, é a de que do novo professor titular se aguarda um pronunciamento, uma manifestação pessoal a respeito dos seus propósitos, do que pensa sobre as questões fundamentais da sua disciplina e do seu ensino.

Como se sabe, dentre os diversos setores do ordenamento estatal, o do processo penal sempre foi um dos mais problemáticos e sujeitos a influências ideológicas de toda espécie, na medida em que tem por função disciplinar a complexa tarefa estatal de aplicação das mais severas sanções punitivas aos culpados, sem se descuidar, ao mesmo tempo, da proteção da liberdade e da dignidade dos inocentes.

Prova disso, e sem pretender ir muito longe na História, são as profundas transformações por que passou o processo penal no último século. Enquanto nas suas primeiras décadas, e sob influência do ideal de "defesa social" reclamdo pelo positivismo criminológico, constituiu instrumento rotineiramente utilizado pelos regimes totalitários para impor ao individuo o medo do indefinido, situação que foi tão bem descrita por Kafka, no clássico "O Processo", por isso mesmo o processo penal adquiriu no PósGuerra o status de terreno preferencial para a afirmação dos valores mais significativos para a pessoa humana nas Constituições e nos textos internacionais de direitos.

De fato, a consagração constitucional das garantias processuais-penais, especialmente a partir da Constituição da República italiana, de 1948, e dos textos fundamentais português, de 1974, espanhol, de 1976, e brasileiro, de 1988, foi acompanhada pela significativa consagração dessas mesmas garantias em documentos internacionais como a Declaração Universal dos Direitos do Homem (1948), o Pacto Internacional sobre Direitos Civi e Políticos (1966) e as Convenções Européia e Americana sobre Direitos Humanos, de modo a se falar atualmente num verdadeiro sistema de garantias processuais que não se exaure em prescrições particulares, mas está fundamentado na coordenação de várias garantias concorrentes, aptas a tornar cada vez mais segura e eficaz a proteção do indivíduo.

A referência a esse movimento universal em direção a uma concepção garantista do processo penal não significa, contudo, que possam ser consideradas superadas as tendências autoritárias que sempre marcaram esse setor da atividade estatal. Ao contrário, cada vez mais se mostram evidentes as contradições entre as prescrições constitucionais e o modo concreto de atuação do aparato punitivo, a distância entre a normatividade e a efetividade das mencionadas garantias, bem como os perigosos retrocessos, que podem ser facilmente identificados.

$\mathrm{O}$ inquietante crescimento dos índices de criminalidade, em especial aqueles relacionados às suas formas mais violentas e perniciosas, como as atividade de organizações criminosas, o tráfico de drogas, o terrorismo, tem levado o legislador, no Brasil, e em todas as partes do mundo, a editar medidas excepcionais de emergência, 
cujo denominador comum é justamente a restrição ou supressão das garantias penais ou processuais, como se isso pudesse constituir freio a tais formas de delinquieencia ou, ainda, pudesse tornar mais eficazes as tarefas da repressão. Pretende-se, na verdade, atingir o ideal absurdo e contraditório de uma "Justiça sem Direito", em que os fins, nem sempre muito claros, possam justificar os meios empregados.

Outro fenômeno muito atual também tem produzido uma afronta diária e insidiosa aos princípios garantistas tão duramente solidificados na consciência universal: trata-se daquilo que Antoine Garapon denomina a "democracia de opinião" em que a Justiça, os meios de comunicação de massa e a opinião pública mesclam-se para criar um ambiente de envolvimento, de efervescência, indignação e compaixão em torno de certos temas e acontecimentos, quase sempre apresentados sob uma qualificação penal.

Trata-se, sob a óptica processual, de uma nova Inquisição, que subverte terrivelmente os valores mais fundamentais ao exercício do poder punitivo numa sociedade democrática. A cena judiciária é deslocada do ambiente sereno da sala de audiências - em que a verdade processual é estabelecida racionalmente por meio das provas e após o debate contraditório das partes - para os espaços dos meios de comunicação nos quais se apresenta ao leitor ou telespectador uma verdade imediata $\mathrm{e}$ emocional. O juiz independente e imparcial, que precisa explicitar na motivação das sentenças as suas razões de decidir, é substituído indevidamente pelo jornalista, só comprometido com a repercussão do caso. $O$ valor de igualdade que fundamenta a regra de obrigatoriedade da ação penal cede lugar à escolha de fatos espetaculares ou segundo os interesses mais imediatos da empresa jornalística. A simples denúncia é imediatamente assimilada à condenação definitiva, em flagrante desrespeito à presunção de inocência, em flagrante desrespeito à presunção de inocência, que por sua vez é tida como favor indevido ao delinqüente. A função social da defesa, que constitui garantia da própria jurisdição, é confundida muitas vezes com uma ignóbil cumplicidade com o crime. As simples suspeitas já são equiparadas a provas irrefutáveis de culpabilidade. Os recursos perdem a salutar função de prevenir os erros judiciários para se converterem em manobras indevidas para a procrastinação da solução da causa e assim por diante.

Tudo isso está a indicar que o estudo e o ensino do processo penal não podem limitar-se à análise dos textos legais, ao simples exame sistemático das normas de Direito Positivo, exigindo, ao contrário, uma visão mais ampla dos complexos fenômenos sociais, políticos e culturais envolvidos comas atividades da repressão penal. A função do jurista deve estar voltada não só à crítica das referidas contradições, mas principalmente à sua superação pela afirmação dos valores da liberdade, igualdade e respeito à dignidade da pessoa humana no âmbito da Justiça criminal. Não se trata de tarefa cômoda, num terreno sempre sujeito a avanços e retrocessos, mas como ressalta Alberto Binder, é importante definir o lado em que se está.

Finalmente, a terceira e certamente a mais significativa mensagem que extraio do ritual observado nesta cerimônia decorre da calorosa presença dos familiares e amigos, que serve para avivar no meu espírito os sentimentos de humildade e gratidão. 
Essa presença impõe o reconhecimento de que na trajetória realizada não estive só, o que vale dizer que para a realização do projeto pessoal hoje concretizado contribuiram muitas pessoas, algumas que hoje me honram com o seu comparecimento solidário e outras que, infelizmente, aqui não estão, mas que ocupam um lugar destacado na minha memória.

Com todas elas quero partilhar esta conquista e expressar a mais profunda, emocionada e sincera gratidão.

Antes de tudo, à minha família, que sempre me proporcionou um ambiente cheio de afetividade, alegria e respeito aos valores cristão. Aos meus pais, que me deram a vida e o exemplo de trabalho e honradez; aos meus tios, sempre muito presentes na minha formação; às minhas irmãs e meu irmão, ao meu cunhado e sobrinhos, aos primos e primas, sempre incentivadores dos meus projetos.

De modo muito especial, o meu obrigado à Isabela, minha mulher, companheira e cúmplice nos últimos quase trinta anos, e às nossas filhas Mariângela $\mathrm{e}$ Gabriela, pelo apoio constante ao meu trabalho e sobretudo pela dedicação, pelo carinho e pela compreensão.

Também quero agradecer aos meu amigos: aos amigos-professores, que desde os bancos da escola primária e secundária incutiram no meu espírito o desejo de sempre aprender mais; aos amigos-colegas de todos os cursos que freqüentei e, muito especialmente os da Turma de 1969 desta Faculdade, com os quais dividi experiências e com os quais partilhei sobretudo os ideais de liberdade e civismo destas Arcadas, numa época especialmente difícil da vida nacional; aos amigos do Ministério Público, da Magistratura e da Advocacia, que me transmitiram muitas lições, que procuro sempre repassar aos meus alunos.

A minha gratidão muito especial aos meus amigos desta Faculdade de Direito: aos funcionários sempre solícitos e dedicados; aos professores, que pela sua cultura e inteligência proporcionam aos que desfrutam de sua convivência momentos incomparáveis de alegria espiritual; particularmente, ao meu amigo Antonio Scarance Fernandes, companheiro nesta caminhada, a minha saudação.

Propositadamente por último, o meu mais caloroso agradecimento ao corpo discente desta Faculdade, que representa sem dúvida o nosso maior patrimônio. Em especial, aos meus queridos alunos da graduação e da pós-graduação que, com sua atenção, suas dúvidas e seu posicionamento crítico, muito me tem ensinado. 


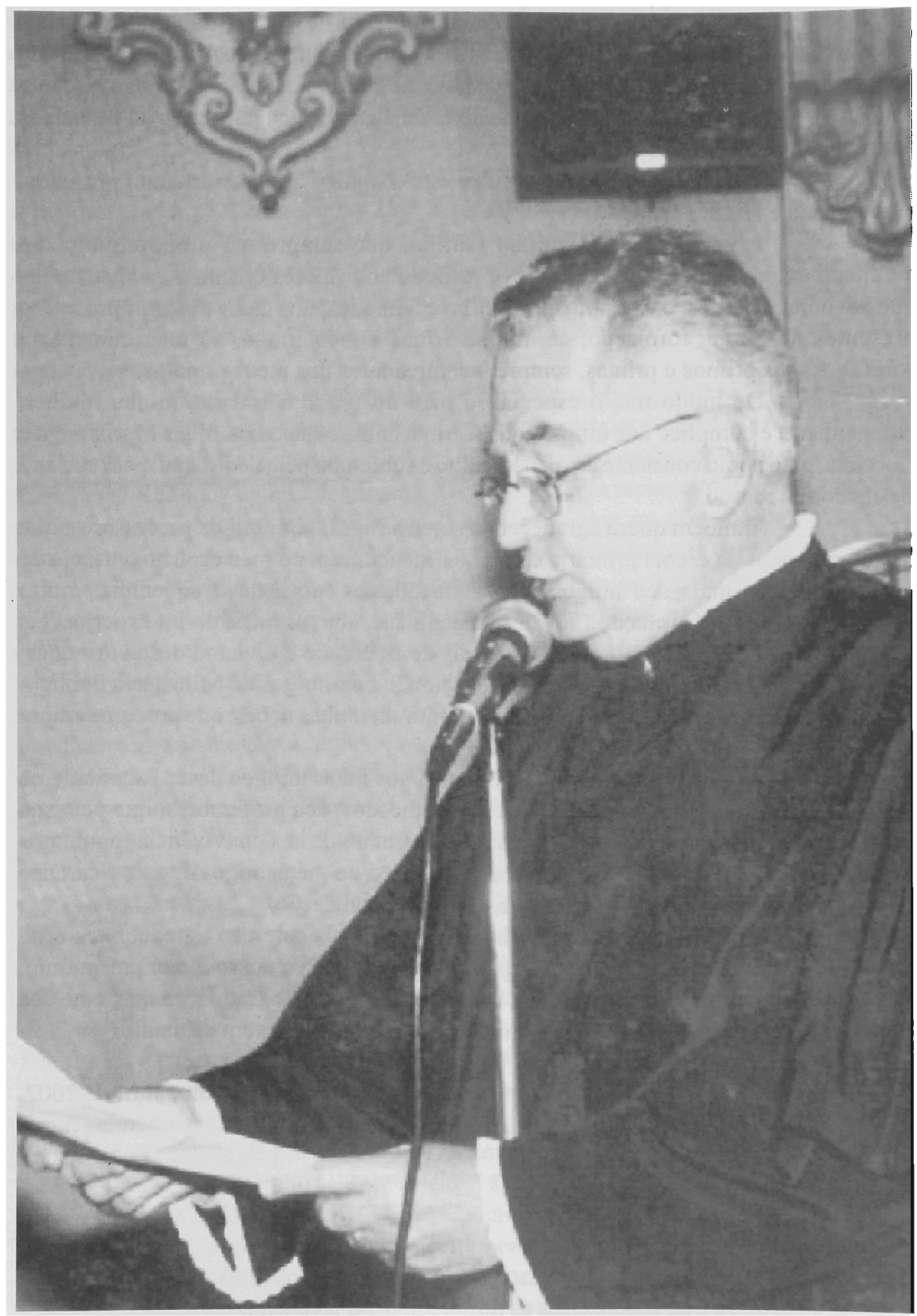

Professor Titular Antonio Magalhães Gomes Filho 